\title{
Modeling the Holocene slip history of the Wasatch fault (Utah)
}

\author{
Meike Bagge (1,2), Andrea Hampel (1), and Ryan Gold (3)
}

(1) Leibniz Universität Hannover, Institut für Geologie, Hannover, Germany (hampel@ geowi.uni-hannover.de), (2) Helmholtz-Zentrum Deutsches GeoForschungsZentrum (GFZ), Telegrafenberg, 14473 Potsdam, Germany, (3) U.S. Geological Survey, 1711 Illinois St, Golden, CO 80401, U.S.A

The Wasatch fault zone constitutes the eastern boundary of the actively extending Basin and Range Province (Utah) and poses a significant seismic hazard to the metropolitan areas along the Wasatch Range. A wealth of paleoseismological data document $\sim 24$ surface-rupturing $\mathrm{Mw} \geq 7$ earthquakes along the Wasatch fault during the last 6400 years. Here we simulate the Holocene earthquake sequence on the Wasatch, Oquirrh-Great Salt Lake and West Valley faults using three-dimensional finite-element modeling with the goal to calculate co- and postseismic Coulomb stress changes and to evaluate the slip and magnitude of hypothetical present-day and future earthquakes. Our results show that a good fit between modeled and observed paleoevents and time-integrated slip rates can be achieved within the uncertainties of the paleoseismological record and model parameters like the fault geometry. The Coulomb stress change analysis for selected paleoearthquakes shows that maximum positive stress changes are induced on receiver faults located along-strike of the source fault, while receiver faults parallel to the source fault are generally located in stress shadow zones. Postseismic viscoelastic relaxation considerably modifies the coseismic stress changes; the resulting transient stress changes are recognizable for more than $100 \mathrm{yr}$ after the event. The modeled present-day state of Coulomb stress changes shows that the Brigham City, Salt Lake City and Provo segments of the Wasatch fault are prone to failure in a $\mathrm{Mw} \geq 6.8$ earthquake. Our study shows that the simulation of an entire earthquake sequence based on a paleoseismological record is feasible and facilitates identification of possible gaps and inconsistencies in the paleoseismological record. Therefore, forward modeling of earthquake sequences may ultimately contribute to refining seismic hazard estimates. 